\title{
Sexing Sand Fly Pupae (Diptera: Psychodidade: Phlebotominae)
}

\author{
Beatriz Gomes Brazil, Reginaldo Peçanha Brazil ${ }^{+}$
}

Laboratório de Leishmanioses, Centro de Pesquisas René Rachou-Fiocruz, Av. Augusto de Lima 1715, 30190-002 Belo Horizonte, MG, Brasil

We describe a technique to separate male and female pupae of sand flies. This has reduced the labour to separate flies after emergence and also allows the isolation of unmated adults for behavioural and physiological studies.

Key words: Insecta - sand flies - sex - pupae - morphology

Manipulation of adult sand flies involving aspiration and transfer between recipients is stressful to the insect and the separation of large numbers of male and females is a laborious and timeconsuming job. Damage to the insects is also undesirable when these are used in morphological studies. Although separation of the sexes in the immature stages is very difficult for most insects, it is easily achieved for phlebotomine sand flies. Morphological differences in the last segment of male and female pupae of sand flies were pointed out by Barreto in 1940 and also by Mangabeira (1942a,b) when studying the life cycle of few Brazilian species. Since these observations were published, distinction of the sexes at the pupal stage has not been pursued by sand fly researchers, although advances have been made in the colonisation of various species during the last decade, making it possible to focus attention on different aspects of the biology of these insects. Researchers are now concerned with behaviour as well as with the morphophysiology of the male and female besides the role of the different species as vectors of the disease. Thus, a routine procedure for sexing sand fly pupae becomes a standard requirement to obtain adult insects for use in these studies (Ward et al. 1987, 1990).

During a training period in the laboratory of Dr Richard Ward at the Liverpool School of Tropi-

\footnotetext{
This work was supported by CNPq (Pronex), Capes and Fiocruz.

${ }^{+}$Corresponding author. Fax: +55-31-295.3115. E-mail: rpbrazil@cpqrr.fiocruz.br

Received 15 June 1999

Accepted 4 January 2000
}

cal Medicine (1988/1989) we acquired knowledge of how to sex sand flies at the pupal stage. This has allowed us to avoid manipulation of the adults in our work. The methodology we have established has been used successfully for ten years by ourselves and several colleagues. This methodology was also used to sex pupae of Lutzomyia longipalpis, L. intermedia, L. whitmani, L. migonei and $L$. rene $i$ with success.

The following materials are required for this work: a large petri dish lined with a disc of filter paper, a soft thin paint brush (no. 0), a small container of distilled water in which to dip the paint brush, and a stereo microscope.

Procedures: (1) pupae are obtained by any of the methodologies already established for the colonisation of sand flies (Modi \& Tesh 1982, Brazil et al. 1997); (2) the filter paper is moistened with distilled water; (3) pupae are transferred from the breeding pots with the help of the paint brush and left for $5 \mathrm{sec}$ to $10 \mathrm{~min}$ to moisten the larval exuvia which remains attached to the last pupal segment; before collecting each specimen the paint brush must be dipped in distilled water; (4) the larval exuvia is gently removed with the help of the paint brush so that the last segment of the pupa is revealed. Manipulation of the pupae should be done under the stereoscopic microscope. The separation of male and female pupae involves examination of the last pupal segment which in the male is larger, more rounded and paler than the previous one (Figure). The female body segments decrease in size from the cefalothorax to the tip of the abdomen, so that the last abdominal segment is the smallest of all. This difference in segment proportion is due to the relatively long size of the male external genitalia, consisting of paired styles, coxites, lateral lobes and parameres. After 


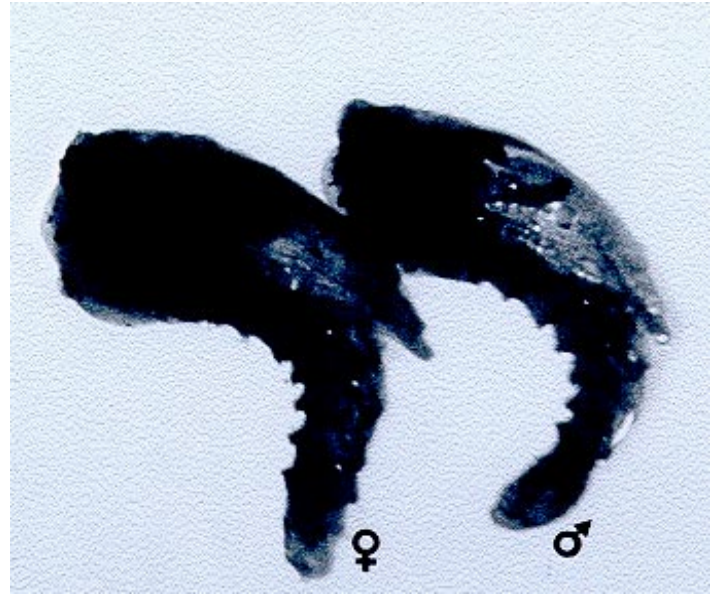

Male and female pupae of Lutzomyia longipalpis.

sexing the pupae, male and female can be separated in different recipients. In this way we avoid the need to separate the sexes after emergence which is much more difficult and may stress the insects or damage the wings, legs, antennae, palps or proboscis. It also allows the isolation of unmated adults which may be required for on behavioural and physiological studies. The possibility of error in the identification of the sexes by a trained person is minimal, although to ensure complete success that all the objects used should be clean and free of fungal contamination. We recommended that brushes be washed in $70 \%$ alcohol and rinsed thoroughly in sterile distilled water before use. The manipulation of the pupae should occur on the third day after pupation, since, at this age, the pupal integument has thickened and become darker al- though emergence is not imminent. This procedure is necessary because of the grater susceptibility to mechanical damage of the recently pupated insects or those close to emergence.

\section{ACKNOWLEDGEMENTS}

To Genilton José Vieira, IOC- Fiocruz for the photographs and Dr Bruce Alexander for critical reading of the manuscript.

\section{REFERENCES}

Barreto MP 1940. Morfologia dos ovos, das larvas e das pupas de Phlebotomus intermedius Lutz e Neiva, 1912 (Diptera:Psichodidae). An Fac Med S Paulo 16: 91-105.

Brazil RP, Carneiro VL, Andrade Filho JD, Alves JCM, Falcão AL 1997. Biology of Lutzomyia lenti (Mangabeira) (Diptera:Psychodidae). An Soc Entomol Brasil 26: 191-193.

Mangabeira O 1942a. 9a contribuição ao estudo dos Phlebotomus (Pressatia) triacanthus Mangabeira, 1942. Mem Inst Oswaldo Cruz 37: 241-250.

Mangabeira O 1942b. 11 1 contribuição ao estudo dos Phlebotomus (Diptera:Psychodidae). Phlebotomus oswaldoi Mangabeira, 1942. Mem Ins Oswaldo Cruz. 37: 287-295.

Modi GB, Tesh R 1982. A simple technique for mass rearing Lutzomyia longipalpis and Phlebotomus papatasi (Diptera:Psychodidae) in the laboratory. $J$ Med Entomol 20: 568-569.

Ward RD, Morton I, Lancaster V, Smith P, Swift A 1987. Bioassays as an indicator of pheromone communication in Lutzomyia longipalpis (Diptera: Psychodidae). NATO-ASI Series 163: 235-243.

Ward RD, Morton IE, Brazil RP, Trumper S, Falcão AL 1990. Preliminary laboratory and field trials of a heated pheromone trap for sandfly Lutzomyia longipalpis (Diptera:Psychodidae). Mem Inst Oswaldo Cruz 85 : 445-452. 